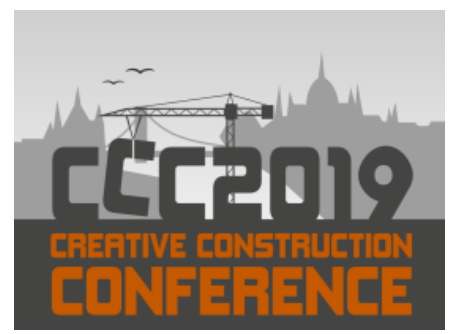

Available online at 2019.creative-construction-conference.com/proceedings/

CCC 2019

Proceedings of the Creative Construction Conference (2019) 050

Edited by: Miroslaw J. Skibniewski \& Miklos Hajdu

https://doi.org/10.3311/CCC2019-050

Creative Construction Conference 2019, CCC 2019, 29 June - 2 July 2019, Budapest, Hungary

\title{
Implementing Progressive Design Build, A Case Study: UW West Campus Utility Plant
}

\author{
Luming Shang ${ }^{a}$, Giovanni C Migliaccio ${ }^{a^{*}}$ \\ ${ }^{a}$ The University of Washington, Department of Construction Management, Seattle, WA 98195, USA
}

\begin{abstract}
Design-Build (DB) contracts have been used for many years in the United States of America. The award of a DB contract frequently relies on evaluating which DB team provides for the best value through a multi-criteria evaluation process with price being one of the most important criteria for team selection. To ensure project success, the owner usually has to spend adequate efforts and time during scoping and early design to prepare a program, scope, and budget, which are defined enough to undergo procurement and price generation. This, however, has become a potential burden for the owner, and may lengthen the project development duration. As an alternative to traditional Design-Build, Progressive Design-Build (PDB) provides for the selection of the DB team prior to deciding the program and/or budget for the project. PDB has the advantage of maintaining a single point of accountability and allowing to select a team based mainly on their qualifications with a limited price consideration. Under PDB, the selected team will work with the agency's stakeholders during the early design while helping the owner to balance scope and budget. The key to understanding PDB, however, lies in the ongoing and complete involvement of the owner in the early design phase. Due to the differences between PDB and the other project delivery methods (e.g., traditional DB), several factors must be considered carefully to assure the successful implementation of PDB. However, information on PDB is lacking because of its novelty. This paper aims to investigate the implementation of PDB by conducting a case study of the University of Washington's pilot PDB project for completing the West Campus Utility Plant (WCUP). The project's entire delivery process and organizational structures are summarized and presented.
\end{abstract}

(C) 2019 The Authors. Published by Budapest University of Technology and Economics \& Diamond Congress Ltd.

Peer-review under responsibility of the scientific committee of the Creative Construction Conference 2019.

Keywords: Progressive Design Build; Project Delivery Method

\section{Introduction}

Design-Bid-Build (DBB) is the project delivery method traditionally used in public works. However, its efficiency has been questioned due to its vulnerability to construction claims, busted budgets and schedule delays. Design-Build (DB) is one of the alternative methods designed to overcome the inherent drawbacks of DBB. In the United States, DB has been used by public owners for decades. In a DB project, a single entity contracts with the owner to provide design and construction services. The solicitation is usually based on one of three approaches, including low bid, one-step best value, and two-step best value [1], and the bidding evaluation focuses on two aspects primarily - qualifications and price. Also, the owner usually contracts with an independent design consultant to develop conceptual design 
Shang and Migliaccio / Proceedings of the Creative Construction Conference (2019) 050 https://doi.org/10.3311/CCC2019-050

necessary to the issuance of a Request for Qualifications (RFQ) and a Request for Proposals (RFP). Upon response to the solicitation, the winning team is selected based on the design proposal and price. A traditional DB requires the RFP to be as specific as possible to explicitly state the project requirements, which is usually the last chance for the owner to clarify their expectations [2].

The success of a DB project relies highly on the owner's early design. In the RFQ phase, the early design documents provide prospective contractors with the information necessary to assemble the right team for the competitions. In the RFP phase, a comprehensive early design package helps DB teams eliminate confusions or misunderstandings and start from the same basis of design. Additionally, a well-designed preparatory document can reduce the uncertainties and the potential problems of subsequent change orders. Therefore, in order to ensure the project success, the owner usually has to spend adequate efforts while developing the early design documents so that they provide for a clearly defined program, scope, and budget. This, however, has become a potential burden for the owner, and to a certain extent, has lengthened the overall project duration.

Recently introduced in procurement code, Progressive Design-Build (PDB) is an emerging alternative to the traditional $\mathrm{DB}$, which determines the DB team prior to setting the program and/or budget for the project. PDB maintains a single point of accountability for the team selection and evaluates competing teams based on their qualifications with a limited consideration of price factors. The selected DB team works with the owner to complete the early design, while helping to balance scope and budget. The key to understanding PDB, however, lies in the on-going and complete involvement of the owner in the design phase. The owner should be aware that every decision has an implication in terms of costs, and that any change to these decisions potentially creates a new cost. Knowing the costs associated with the project in a timely manner increases the owner's perception of the contractor as an ally, and the team is no longer seen as always ready to take advantage of the circumstances in order to increase its profit margin. Innovation is fuelled by a collaborative environment in PDB, and because of the continuous involvement of the owner, it is possible to obtain feedback and directives on time, during both the design and construction phases.

To improve understanding of PDB, the authors have developed a case study paper based on the pilot implementation of PDB by the University of Washington for the delivery of the West Campus Utility Plant; thus this paper describes the procurement process of this pilot PDB project. First, we discuss the differences between PDB and traditional DB; next, the case study is presented; finally, lessons learned are listed.

\section{Distinguishing PDB From Traditional DB}

Under traditional DB, some teams are not selected due to the relative high price of their outstanding design alternatives. This is especially true when the price criterion is highly weighted, such as in low bid procurement. On the other hand, PDB allows the owner to choose the most appropriate team based primarily on qualifications and to complete the design together with the selected team. The major differences between PDB and traditional DB derive from three aspects, including its solicitation process, contractual structure, and risk allocation.

In terms of the solicitation, a complete basis of design is no longer necessary prior to the team selection for PDB projects. In the RFP phase of the traditional DB project, the shortlisted design-builders submit a detailed technical proposal with a design sufficient to define scope and price. The proposal is typically accomplished based on a baseline design provided by the owner, with technical specifications. However, this solicitation process conversely increases the owner's burden, as it requires the owner to spend more time and money upfront to develop a basis of design and it also places higher responsibilities for the cost of changes on the owner. Moreover, the traditional DB also has a potential negative impact on innovation since the designer does not have discretion over the whole design. PDB deals with these problems by involving the DB team in the design phase from the very beginning. Very low or even no design effort is required before the contract is awarded, which allows the owner to save time and money through a streamlined procurement process. Additionally, it shortens the procurement time, as the candidate teams no longer need to develop a portion of the design in support of their proposal. From the owner's point of view, the preparation costs and time for RFQs and RFPs are relatively low in PDB and the evaluation is easy due to the qualification-based 
Shang and Migliaccio / Proceedings of the Creative Construction Conference (2019) 050 https://doi.org/10.3311/CCC2019-050

selection (QBS). From the perspective of DB teams, PDB is more attractive because it requires less effort (e.g., cost and time) to respond to the solicitation.

In terms of contractual structure, PDB projects usually have simpler contracts comparing to traditional DB projects. Commonly, a PDB project relies on two separate contracts, including a Preliminary Agreement and a Construction Contract; this creates a two-phased approach. Initially, the Preliminary Agreement is executed with the main goal of advancing design to a level that can be priced. The target level of design is typically around the traditional Design Development (DD) stage, but this can change as agreed by both parties. While the Preliminary Agreement is in place, project accounting is open-book, so the DB team is compensated on an hourly basis to develop design documents enough to define scope and price. During this phase, the design-builder also performs a wide range of pre-construction services, including constructability reviews. Once the design evolves to a level leading to a mutually agreed price, the execution of the Construction Contract initiates a separate contracting phase, which is based on the deliverables from the Preliminary Agreement. Its scope is similar to a traditional DB contract, in short to complete the design and build the project at the agreed price. Some agencies execute a separate contractual document for this phase; others amend the Preliminary Agreement. The choice between these two pathways appears dependent on both agency's preferences and project type and complexity. Since the DD documents were developed collaboratively and provide only for an intermediate level of design completeness, the owner may bear additional risks due to varying interpretations of the scope during the second contractual phase.

The Preliminary Agreement is awarded based primarily on qualifications, while the second contract can be based on two pricing methods: cost plus with Guaranteed Maximum Price (GMP) or Lump Sum (LS). The level of design detail used in price estimation is typically higher in PDB (around 60\%) than in traditional DB (approximately 35\%). Under PDB, the collaborative design process continues into the second phase since the design needs to be completed and the owner is deeply involved. During this second contract phase, the owner participates in decisions about the scope while relying on price information provided by the DB team. Since the price has already been set into the Design-Build contract, these decisions typically include some scope trade-offs. The owner can also use the project contingency and change order process to add or modify specific scope elements, although the goal of the first contract phase (i.e. the Preliminary Agreement) is to minimize the need for such change orders. The open-book contractual terms allow for owner participation and flexibility in on-going design, redesign, scope additions, re-estimates, and value considerations [3]. Under PDB, as the design progresses, the DB contractor can procure subcontractor design assistances and bids, thus providing the owner with a more firm cost for major elements of works [4].

In terms of responsibility and risk, the owner has a fairly large responsibility in PDB projects due to the intense involvement during the entire process, especially for the design phase. Thus, it requires the owners to be well informed regarding the project needs and requirements. While PDB does not require the owner to have a basis for design in the RFP, doing so can help simplify the owner's responsibilities during the design collaboration of the Preliminary Agreement. A good basis of design in the RFP can be particularly valuable when there are multiple stakeholders within the owner's organization who all have expectations that need to be preserved. It can alleviate concerns about certain project characteristics being lost during the busy and typically time constrained design phase.

\section{The PDB Case Study}

To provide a comprehensive understanding of PDB and contribute to best practices for future implementation of PDB, a case study of a pilot PDB project in Washington State has been conducted through analysing project documents, attending project meetings, and conducting semi-structured interviews with the different stakeholders (e.g., project owners and contractors).

\subsection{Project Description}

In 2013, the University of Washington (in Seattle) awarded a project to build a new utility plant, named the West Campus Utility Plant (WCUP), which serves as an extension of the University's Power Plant. The WCUP is intended 
Shang and Migliaccio / Proceedings of the Creative Construction Conference (2019) 050 https://doi.org/10.3311/CCC2019-050

to produce chilled water to meet both process and comfort cooling needs for a variety of facilities in the West and South Campus areas of the University. The plant is also expected to generate electrical power to meet emergency/standby needs.

The WCUP development was planned to occur in two utility expansion phases. In the first phase, a plant containing generators, chillers, cooling towers and associated equipment in order to produce 6 megawatts (MW) of emergency power and 4,500 tons of chilling capacity was built and placed in operations. A second phase foresees the opportunity to approximately double both the production of power and chilling capacity (i.e., $12 \mathrm{MW}$ of emergency power and 10,500 tons of chilling capacity). During the first phase, a building able to host the two utility expansion phases was built. This case study is based on the first phase of the project.

\subsection{The Delivery Process}

Due to the potential changes in the future plans of the utility expansion, there was a need for a more flexible delivery method. In this project, the owner (UW) selected a highly collaborative PDB process that was new to both the University and the state.

PDB in the WCUP is preceded by a planning phase and follows with a solicitation phase with two sub-phases, including an RFQ phase and an RFP phase. Each phase includes several activities, and the transition from one phase to another is marked by the achievement of a milestone, which usually consists of the issuance of a procurement or contractual document. Team qualification is the only criterion used in the RFQ phase, while the RFP phase is based on qualifications, the proposed approach to the project, and the legally required price-related factor. The DB team has been decided after the solicitation phase. The owner and the selected team then proceeded to signing two contracts, named as preliminary agreement and construction contract respectively, concerning the completion of the design and construction. An overview of the delivery process is illustrated in Figure 1.

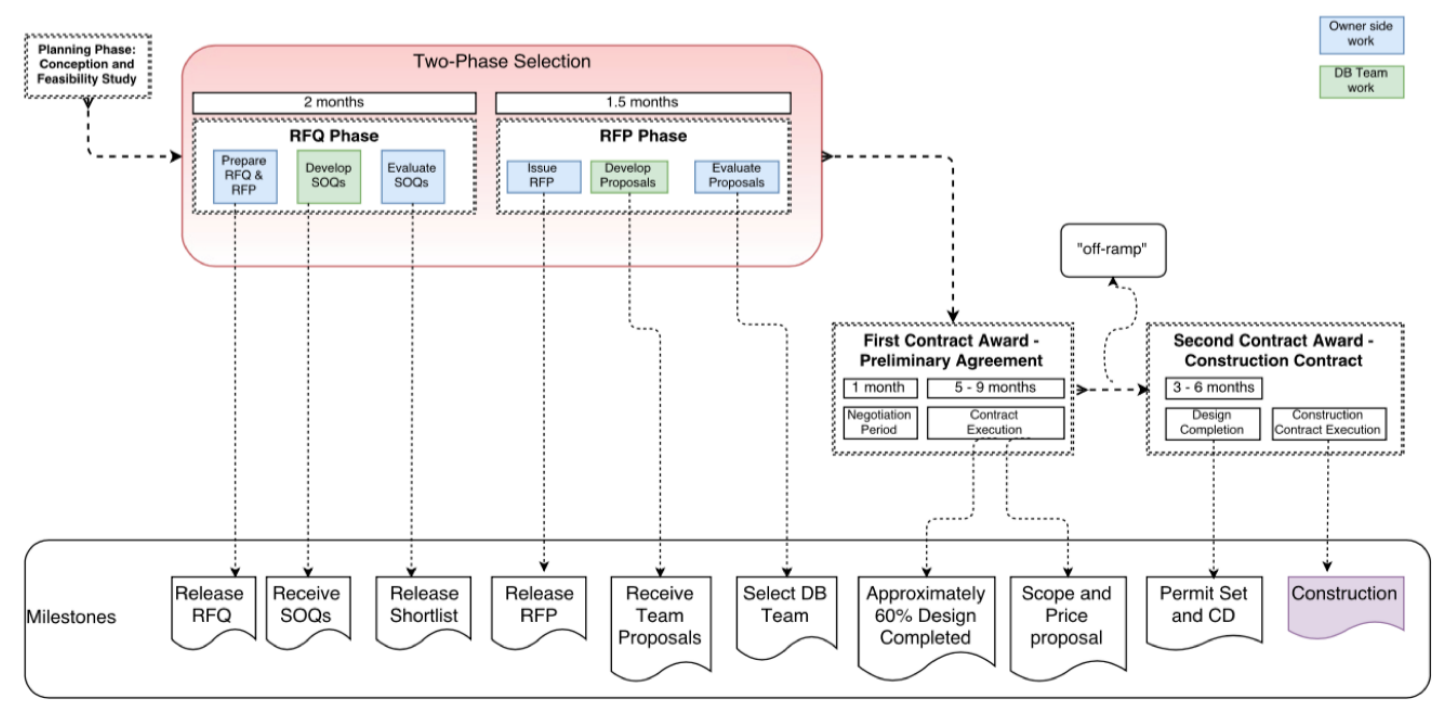

Fig. 1. Overview of procurement process with phase durations and milestones

\subsubsection{The Planning Phase}

The planning phase happens before the solicitation. Initially, the project needs and utility demands were identified by the UW Facilities Services (FS) department. Later on, the Capital Planning and Development (CPD), the organization responsible for managing capital projects at the UW, initiated a feasibility study and hired consultants to evaluate the feasibility of augmenting the campus emergency power and chilled water capacities and various sites. Based on the feasibility study, the CPD and FS applied to the UW's Board of Regents (BoR) for project authorization. This request contained a project budget (i.e. estimated total project cost), scope of work, and schedule. The BoR approved the 
Shang and Migliaccio / Proceedings of the Creative Construction Conference (2019) 050

https://doi.org/10.3311/CCC2019-050

authorization request in 2013 and confirmed the use of PDB as the delivery method. A project manager from the CPD was assigned as the main contact throughout the life of the project and works closely with the construction entity to ensure schedule and budget adherence. The manager was responsible for organizing and administering the project from the conception to the completion.

\subsubsection{The Solicitation Phase}

Similar to the traditional DB, the solicitation process of the WCUP project included two sub-phases, including a RFQ and a RFP.

\section{$\underline{\text { RFQ Phase }}$}

To determine project priorities and develop a risk management plan, a policy analysis was first conducted by the CPD contract/legal manager and directors. The RFQ documents were developed after this initial policy analysis. The purpose of the RFQ was to generate a shortlist of DB teams entering the RFP phase. The RFQ phase can be further divided into three major steps, including preparation of RFQ documents, interaction with the DB teams, and evaluation of the Statements of Qualification (SOQs).

In the RFQ documents preparation step, the project directors and managers were responsible for developing an initial RFQ draft containing the weighted selection criteria and a description of the process. An industry review (through the Daily Journal of Commerce) was then conducted to recruit suggestions, and based on the feedback the RFQ was revised and finalized. The milestone of this step was the issuance of the RFQ. Different from the past, this RFQ focused more on the qualification of the participating teams.

In the step of interacting with DB teams, the participating teams developed their SOQ based on the issued RFQ. Unlike other projects, the WCUP included no collective meeting between the interested teams and the owner. If the DB team requested further clarification, they were allowed to consult with the unique representative assigned by the owner. The step ended with the candidate teams submitted the SOQs within the prescribed time limits.

In the evaluation step, the Selection Committee (SC), assembled in the beginning of the RFQ phase, evaluated the SOQs through the attribution of a score for each criterion. The points were added up to rank the teams. The three highest scoring teams were shortlisted and invited to participate in the RFP phase.

\section{RFP Phase}

In the RFP phase, the shortlisted teams were not required to design or price an actual proposal, instead, the WCUP project emphasized that the teams should prove their qualifications and the approach for collaboration. Similar to the RFQ phase, the RFP also consisted of three steps, including preparation of RFP package, proposal development, and proposal evaluation and selection.

An RFP package, which contains a) RFP document, b) price factor form, c) two contracts (i.e., preliminary agreement and construction contract), d) general conditions, and e) general requirements, was first prepared by the owner (UW) to explicitly state the project requirements and expectation. According to the characteristics of the PDB, the design requirements in the RFP were relatively brief compared to the traditional DB. The RFP also prescribed the procedures and deadlines for submitting the proposals, and the evaluation process was clarified, including the evaluation criteria with the corresponding weights. The main criteria are summarized in Table 1.

The initial six criteria listed in Table 1 were considered of greater importance and were assigned higher weights. The price factor (Criterion 11) did not carry a heavy weight; still, it indicated a price range for the price proposed by the winning team for the second contract. Once the preparation step was completed, the RFP package was released to the three eligible candidates.

In the proposal development, the owner arranged individual meetings with shortlisted teams, referred as proprietary meetings, to help the team get clarification on both the evaluation criteria and the selection process. The shortlisted teams would have the chance to present their preliminary proposals and communicate with the University's 
Shang and Migliaccio / Proceedings of the Creative Construction Conference (2019) 050 https://doi.org/10.3311/CCC2019-050

Architectural Commission, the SC and other executives. The owner posted pertinent addenda online to ensure each team competing with the same level of information.

Table 1. The main proposal evaluation criteria in the WCUP project

\begin{tabular}{|c|c|}
\hline \multicolumn{2}{|r|}{ Evaluation Criteria } \\
\hline 1 & Essential characteristics of, and general approach to, managing the DB project (e.g., the understanding of PDB method) \\
\hline 2 & Engineering approach (e.g., the team's strategy to develop the project in terms of functionality and quality of the work) \\
\hline 3 & Approach to building architecture and urban design (e.g., how to stick to the UW architectural goal) \\
\hline 4 & $\begin{array}{l}\text { Management and approach to design development (e.g., the means of interaction within the team and between the team and } \\
\text { owner during the design) }\end{array}$ \\
\hline 5 & $\begin{array}{l}\text { Management and completing approach to design and construction (e.g., how changes during the project design and } \\
\text { construction will be managed) }\end{array}$ \\
\hline 6 & $\begin{array}{l}\text { Management and approach to commissioning and training (e.g., how the team will train the UW staff to allow the smooth } \\
\text { transition to operations) }\end{array}$ \\
\hline 7 & Ability to meet time and budget requirements \\
\hline 8 & Acceptance of contract, bonding and insurance (as a Pass or Fail decision) \\
\hline 9 & Workload factor (e.g., impact of activities outside the project that may affect the team's ability to carry out the work) \\
\hline 10 & Location of the team (as it may impact the communication capability during the work) \\
\hline 11 & Price factor, including the percentage rate for Overhead and Profit of the DB contractor \\
\hline 12 & MBWE (Minority and Women owned enterprise) outreach plan \\
\hline
\end{tabular}

In the evaluation step, the shortlisted teams submitted their proposals in two different envelopes - one containing bonding and insurance letters, and price factor; and another containing the answers to the remaining criteria. The UW's project managers scheduled the deadline of the proposal submission, collected the responded proposals, discarded the team that failed to meeting Criterion $8(\mathrm{P} / \mathrm{F})$ with the independent financial consultant, and then forwarded the eligible team proposals to the SC who would decide the team's score for each criterion and rank the teams based on the sum of scores. The winning team was determined based only on the evaluation scores.

\subsubsection{The Contracting Phase}

The Contracting phase consisted of two sub-phases, including a Preliminary Agreement and a Construction Contract. The first contracting phase started by a negotiation between the owner and the winning team and followed by the execution of the Preliminary Agreement. The Agreement required the owner and the DB team to collaboratively generate a Work Plan which included (1) a scope of work and a schedule of activities; (2) the anticipated hours needed to complete each activities; (3) the individuals who will be responsible for each activity and the corresponding hourly rates; and (4) the deliverables - approximately $60 \%$ design with a design narrative and a price. The Preliminary Agreement also prescribed the deadline and the maximum payment, which, however, can be adjusted by mutual agreement between the owner and the DB team. If the owner failed to reach an agreement with the highest scoring finalist, the owner could consider contracting with the next highest scoring finalist. In the studied case, the selected DB team was composed of a general contractor (GC) and a number of design and engineering firms. The GC was the leader of the team and entered into separate contracts for architectural design and for engineering design. Additionally, the GC contracted with the major mechanical and electrical subcontractors and all other subs. As such, despite the collaborative team atmosphere where the owner works with all the designers, these entities are contracted directly with the GC.

The second contract dealt with the completion of the design and the construction phase. A lump sum was used in this project. Two different scenarios might happen in this phase. On one hand, the owner and the same DB team from the Preliminary Agreement would continue to sign the second contract and complete the project design and construction collaboratively. On the other hand, an off-ramp clause could be exercised if the owner and the original team failed to reach an agreement regarding the final price of the project or other terms in the second contract. By exercising the off- 
ramp, the owner could use alternative approaches to complete the project. Under the off-ramp, language in the Preliminary Agreement allowed the owner to use design documents provided by the original team. Still, the owner had the right to hire another team to complete the project or execute the project with another delivery method such as DBB. In the WCUP project, the owner continued to work with the original DB team to complete the project under PDB, and the off-ramp option was not used.

\subsection{Project Evaluation}

As the first PDB project to both the UW and the Washington State, the WCUP harvested a satisfactory result from the perspectives of time, budget, and collaboration. Overall, the reactions/feedbacks from all the stakeholders to PDB were positive. The owner and the DB team successfully built a good trust between each other and maintained healthy relationships among all participants. There were no hard disputes during the project delivery period, and the process of figuring out issues with contractors and subs went efficiently.

However, some issues were revealed during the process. From the owner's perspective, the design and collaboration process was generally rigorous, but the cost estimating piece was not applied effectively as expected. For example, different stakeholder groups needed to collaborate with their respective design professionals in their area of focus or expertise, but this dissection poses challenges for the entire design process, which is difficult to be inclusive and efficient.

\section{Conclusion}

As an emerging alternative to Design-Build delivery method, Progressive Design-Build (PDB) provides for the selection of the DB team prior to setting the program and/or budget for the project. PDB allows selecting the DB team based mainly on qualification with a limited price consideration. To have a comprehensive understanding of PDB, this paper conducted a case study based on a pilot PDB project, West Campus Utility Plant (WCUP), which is the first PDB project to the Washington State. The project's entire delivery process (e.g., planning, solicitation, and design and construction), organizational structures, and outcome are summarized and presented in this paper. The learned lessons from the project are also summarized. The findings from the WCUP project are intended to contribute to best practices for future PDB implementation.

\section{References}

[1] Migliaccio, G. C., G. E. Gibson, and J. T. O'connor. "Procurement of design-build services: Two-phase selection for highway projects." Journal of Management in Engineering 25, no. 1 (2009): 29-39. https://doi.org/10.1061/(ASCE)0742-597X(2009)25:1(29)

[2] Lopez del Puerto, Carla, Douglas D. Gransberg, and Jennifer S. Shane. "Comparative analysis of owner goals for design/build projects." Journal of Management in Engineering 24, no. 1 (2008): 32-39. https://doi.org/10.1061/(ASCE)0742-597X(2008)24:1(32)

[3] Grant, J., Budget, design, build. Residential Design \& Build magazine, (2008): pp. 12.

[4] Loulakis, M. (2013, June 4). Progressive Design Build. Retrieved from UIMonline.com: http://uimonline.com/index/webapp-storiesaction/id.964/archive.yes/Issue.2013-06-01/title.progressive-design-build 